\title{
Cuckoo male bumblebees perform slower and longer flower visits than free-living male and worker bumblebees
}

\section{Alessandro Fisogni ${ }^{1,2, *,}$, Gherardo Bogo ${ }^{1,3, \S}$, François Massol ${ }^{4}$, Laura Bortolotti ${ }^{5}$ \& Marta Galloni ${ }^{1}$}

\author{
${ }^{1}$ Department of Biological, Geological and Environmental Sciences, University of Bologna, \\ via Irnerio 42, 40126, Bologna, Italy. \\ ${ }^{2}$ Department of Evolution, Ecology, and Organismal Biology, University of California, Riverside \\ 900 University Avenue, Riverside, CA 92521, USA. \\ ${ }^{3}$ Grupo de Ecología de la Polinización, INIBIOMA (Universidad Nacional del Comahue - CONICET), \\ Quintral 1250, San Carlos de Bariloche, 8400, Argentina. \\ ${ }^{4}$ Université de Lille, CNRS, Inserm, CHU Lille, Institut Pasteur de Lille, U1019 - UMR 9017 - CIIL - \\ Center for Infection and Immunity of Lille, F-59000 Lille, France. \\ ${ }^{5}$ CREA Research Centre for Agriculture and Environment, via di Saliceto 80, 40128, Bologna, Italy. \\ *Corresponding author: a.fisogni@gmail.com \\ $\S$ These authors contributed equally to this work.
}

\begin{abstract}
Cuckoo bumblebees are a monophyletic group within the genus Bombus and social parasites of free-living bumblebees, upon which they rely to rear their offspring. Cuckoo bumblebees lack the worker caste and visit flowers primarily for their own sustenance and do not collect pollen. Although different flower-visiting behaviours can be expected between cuckoo and free-living bumblebees due to different biological constraints, no study has yet quantified such differences. Here, we provide the first empirical evidence of different flower-visiting behaviours between cuckoo and free-living bumblebees. We recorded the flower-visiting behaviour of 350 individual bumblebees over two years in a wild population of the entomophilous plant Gentiana lutea, of which they are among the main pollinators. In cuckoo bumblebees $(28.9 \%$ of the total), we only found males, while we found both workers and males in free-living bumblebees. Cuckoo bumblebees visited significantly more flowers for longer time periods than both free-living bumblebee workers and males within whorls, while differences at the whole-plant level were less marked. Free-living bumblebee males visited more flowers and performed slightly longer flower visits than workers. Behavioural differences between cuckoo male bumblebees and free-living bumblebee workers are likely related to different foraging needs, while differences between cuckoo and free-living bumblebee males may be caused by differences in colony development and a delayed mating period of free-living bumblebees. The longer visits made by cuckoo male bumblebees will likely negatively affect plant reproductive success through increased within-plant pollen flow.
\end{abstract}

Keywords. Bombus, flower-visiting behaviour, Gentiana lutea, plant-pollinator interactions, Psithyrus.

Fisogni A., Bogo G., Massol F., Bortolotti L. \& Galloni M. (2021). Cuckoo male bumblebees perform slower and longer flower visits than free-living male and worker bumblebees. Belgian Journal of Zoology 151: 193-203. https://doi.org/10.26496/bjz.2021.93 


\section{Introduction}

Bumblebees are primitively eusocial bees with an annual life cycle usually divided into three distinct phases. First, a solitary phase involving hibernation of mated gynes (i.e., reproductive females) followed by nest foundation (from late summer to early spring), then a multiplicative phase during which the founding queen produces workers (i.e., non-reproductive females, from mid-spring to mid-summer), and finally a reproductive phase during which males and gynes are produced (mid-late summer) (ALFORD 1975; LHOMME \& HINES 2019).

As in other groups of social insects, social parasitism has evolved in several species of bumblebees, called cuckoo bumblebees (LHOMME \& HINES 2019). There are currently 27 species of cuckoo bumblebees (subgenus Psithyrus) recognized worldwide (LHOMME et al. 2021). These species completely lack the worker caste (i.e., all the female individuals are fertile females) and do not have specialized structures on the hind legs (i.e., corbiculae) to collect pollen to feed their larvae. Consequently, females of cuckoo bumblebees usurp the nests of host social bumblebees (hereafter referred to as free-living bumblebees) almost always killing the host queen to force the host workers to rear their offspring (FISHER 1987).

Bumblebees are important pollinators of both wild flowering plants and crops (e.g., THOMSON \& GOOdell 2001; Pellissier et al. 2012; FrÜND et al. 2013; ANDRIKOPOULOS \& CANE 2018), and a few species are exploited commercially in agriculture (VELTHUIS \& VAN DOORN 2006; GOULSON et al. 2008). As most pollinators, free-living bumblebees show intraspecific differences in foraging behaviour between sexes mainly in relation to offspring provisioning (SMITH et al. 2019). Workers visit flowers to collect pollen to feed the larvae and nectar for energy intake, while males visit flowers to seek nectar to fuel their flight and to look for mates (GOULSON 2010). Consequently, foraging females have generally high levels of flower constancy (RUSSELL et al. 2017), which increase pollination efficiency by transferring conspecific pollen between flowers of a same species (GOULSON 2010). However, male bumblebees can also inadvertently carry large amounts of pollen that can potentially contribute to pollination (JENNERSTEN et al. 1991; OSTEVIK et al. 2010; WOLF \& MORITZ 2014). Although flowervisiting behaviour of free-living bumblebees has been widely studied, behaviour of cuckoo bumblebees remains almost unstudied (but see BATEMAN \& RUDALL 2014), and to our knowledge there is still no assessment of similarities or differences between parasitic and non-parasitic bumblebees.

In this article, we investigate the flower-visiting behaviour of cuckoo and free-living bumblebees in a wild population of the entomophilous plant Gentiana lutea subsp. symphyandra, where both bumblebee types were abundant and among its most important pollinators. Specifically, we aim to answer two main questions: (1) do cuckoo and free-living bumblebees differ in the time spent visiting flowers and in the number of flowers visited, and (2) do cuckoo bumblebees display different foraging behaviours from those of males and workers of free-living bumblebees? An evaluation of the different flower-visiting behaviours between parasitic bumblebees and their hosts would increase our knowledge of their biology and allow us to estimate differences in pollination efficiency with implications for plant fitness.

\section{Material and methods}

\section{Study site and species}

This study was carried out in a natural population of Gentiana lutea L. subsp. symphyandra (Murb.) Hayek situated on the eastern face of Mount Grande (Northern Apennines; Bologna, Italy), within the Habitat Directive site "IT4050002 SIC-ZPS Corno alle Scale" (1380-1460 m a.s.1.; 448'57" N, 1052'10" E). The study population is located in a steep clearing surrounded by a beech (Fagus sylvatica L.) forest. 
Gentiana lutea subsp. symphyandra is a perennial herb growing on mountains of south-eastern Europe that flowers between June and July (Rossi et al. 2015). The tall fertile stems bear several yellow flowers with wide-open corollas of about $4 \mathrm{~cm}$ in diameter (personal observation $\mathrm{MG}$ ), grouped in pseudowhorls (i.e., multiple flowers grouped tightly together around the stem, subtended by two opposite bracts; hereafter: whorls for simplicity) that flower sequentially from the bottom to the top. Flowers of G. lutea are functionally and ecologically generalized (sensu OLLERTON et al. 2007), being efficiently visited by several insect species belonging to four orders (Hymenoptera, Diptera, Coleoptera, Lepidoptera) with different physiological and energetic requirements (Rossi et al. 2014). Among these, bumblebees have the highest pollinator performance, fidelity and visitation frequency in the studied population (ROSSI et al. 2014). Although G. lutea is a self-compatible species, the partial flower dichogamy reduces withinflower selfing, while spontaneous or pollinator-mediated selfing within plant (i.e., geitonogamy) is more likely to occur (Rossi et al. 2014). Seeds developed from self-pollination have lower viability and germination than cross-pollinated seeds (Rossi et al. 2016).

\section{Bumblebee observations and sampling}

Field observations were carried out over a total of six days in two non-consecutive years (three days in both 2013 and 2015), between July $14^{\text {th }}$ and July $23^{\text {rd }}$ each year, during the flowering peak of G. lutea subsp. symphyandra. On each day we performed two observation periods of $45 \mathrm{~min}$ each, one in the morning and one in the afternoon between 11:00 AM and 4:00 PM, except for two days in 2015 when we could only perform one observation period because of bad weather. Observations were carried out by four trained operators in two fixed patches consisting of seven fertile stems each. For each stem, we recorded the number of whorls and the number of open flowers. During the observation periods, we recorded all bumblebee visits to open flowers and noted their type (i.e., cuckoo or free-living bumblebee), species and sex, number of flowers visited per whorl and plant, number of whorls visited per stem, number of stems visited per patch, and the time spent visiting flowers within each whorl. Females were easily identified by the presence of corbiculae and pollen actively collected on the hind tibia, and by other distinguishing features (e.g., shorter antennae, shape of last tergite). Species were identified in the field based on colour patterns and previous knowledge of the taxa present in the area. To further verify visual identifications at the species level, after each observation period we sampled by hand net or directly with plastic tubes bumblebees that visited plants of $G$. lutea in the surroundings of the focal patches. In addition, we collected all bumblebees that visited flowers for more than five minutes during the observation periods. Collected individuals were put in plastic tubes with ethyl acetate and brought to the laboratory for taxonomic identification by some of the present authors (LB, AF, GB, MG) with the help of dichotomous keys. Specimens are stored at the Laboratory of Plant Reproductive Ecology (Department of Biological, Geological, and Environmental Sciences) at the University of Bologna, Italy.

\section{Data analysis}

Since the focus of this article is not to describe temporal patterns of changes and because we did not find significant differences between years in a preliminary analysis, we pooled data from 2013 and 2015 in all analyses. Moreover, in a preliminary analysis we did not find significant differences between species in either the time spent on flowers or the number of flowers visited, therefore we pooled species data within cuckoo and free-living bumblebee types. We used Pearson's product-moment correlation coefficients to test for correlations between the number of flowers visited and the time spent visiting flowers within whorls and plants by bumblebees.

To test whether bumblebees showed differences in the time spent visiting flowers we used linear mixed models (LMMs). We used the log-transformed time (measured in seconds) spent foraging on flowers by individual bumblebees as response variable, and bumblebee type (i.e., males of cuckoo and free-living 
bumblebees, workers of free-living bumblebees) as fixed effect. We tested two separate LMMs for the time spent within whorls and the time spent on the whole plant. In addition, we fitted two different LMMs including the number of whorls displayed by plants as additive factor or in interaction with bumblebee type to test for effects on the time spent on flowers at the whole-plant level. We included the observation interval, nested within day and year, as a random effect to account for temporal changes. In LMMs on the time spent on the whole plant, the best models in terms of goodness-of-fit were chosen based on the Akaike Information Criterion with correction for small sample sizes (AICc), selecting the model(s) with the lowest AICc value (BURNHAM \& ANDERSON 2002). If $\triangle \mathrm{AICc}$ values for some next best models were lower than 2, we used model averaging to calculate a weighted average of the parameter estimates (BURNHAM \& ANDERSON 2002). After selecting the best models we performed pairwise comparisons between bumblebee types by estimating least-squares means with Tukey-adjusted $p$-values (LENTH 2020).

To evaluate differences in the number of flowers visited by bumblebees we fitted generalized linear mixed models (GLMMs) with Poisson error distribution and with the numbers of visited flowers as response variable, bumblebee type as fixed effect and observation intervals nested within day and year as random effects. We tested two separate GLMMs for the number of flowers visited within whorls and the number of flowers visited on the whole plant, and then performed pairwise comparisons between bumblebee types.

Analyses were performed and figures were drawn in R version 4.0.2 (R CORE TEAM 2019) using the R packages ggplot2 (WICKHAM 2016), lme4 (BATES et al. 2015), emmeans (LENTH 2020) and MuMIn (BARTON 2019).

\section{Results}

We observed a total of 350 bumblebees during 7.5 hours of observations over the two years of sampling, corresponding to three species of cuckoo bumblebees and four species of free-living bumblebees (Table 1). Bombus rupestris was the most abundant species among cuckoo bumblebees, while $B$. terrestris and B. lapidarius were the most abundant species among free-living bumblebees (Table 1). Overall, we only found cuckoo bumblebee males, and workers were more frequent than males in free-living bumblebees (ratio 1.6:1). We did not observe any gynes in either bumblebee type.

\section{TABLE 1}

Sample size of cuckoo and free-living bumblebee species observed throughout the study period. Cuckoo bumblebees do not have the worker caste, and no gynes were observed in either bumblebee type.

\begin{tabular}{ccccc}
\hline Species & Bumblebee type & Total & Workers & Males \\
\hline Bombus rupestris & Cuckoo & 91 & - & 91 \\
Bombus sylvestris & Cuckoo & 8 & - & 8 \\
Bombus vestalis & Cuckoo & 2 & - & 2 \\
Bombus terrestris & Free-living & 112 & 101 & 11 \\
Bombus lapidarius & Free-living & 94 & 17 & 77 \\
Bombus pratorum & Free-living & 41 & 33 & 8 \\
Bombus hortorum & Free-living & 2 & 2 & 0 \\
\hline
\end{tabular}


The mean number $( \pm \mathrm{SE})$ of whorls per plant was $4.93 \pm 0.27(\min =4$, $\max =6)$. On average, all bumblebees visited less than two plants per observation interval before leaving the flowering patches (cuckoo bumblebees $=1.45 \pm 0.1$, free-living bumblebees $=1.48 \pm 0.06$ plants visited). We found significant positive correlations between the number of visited flowers and the time spent both within
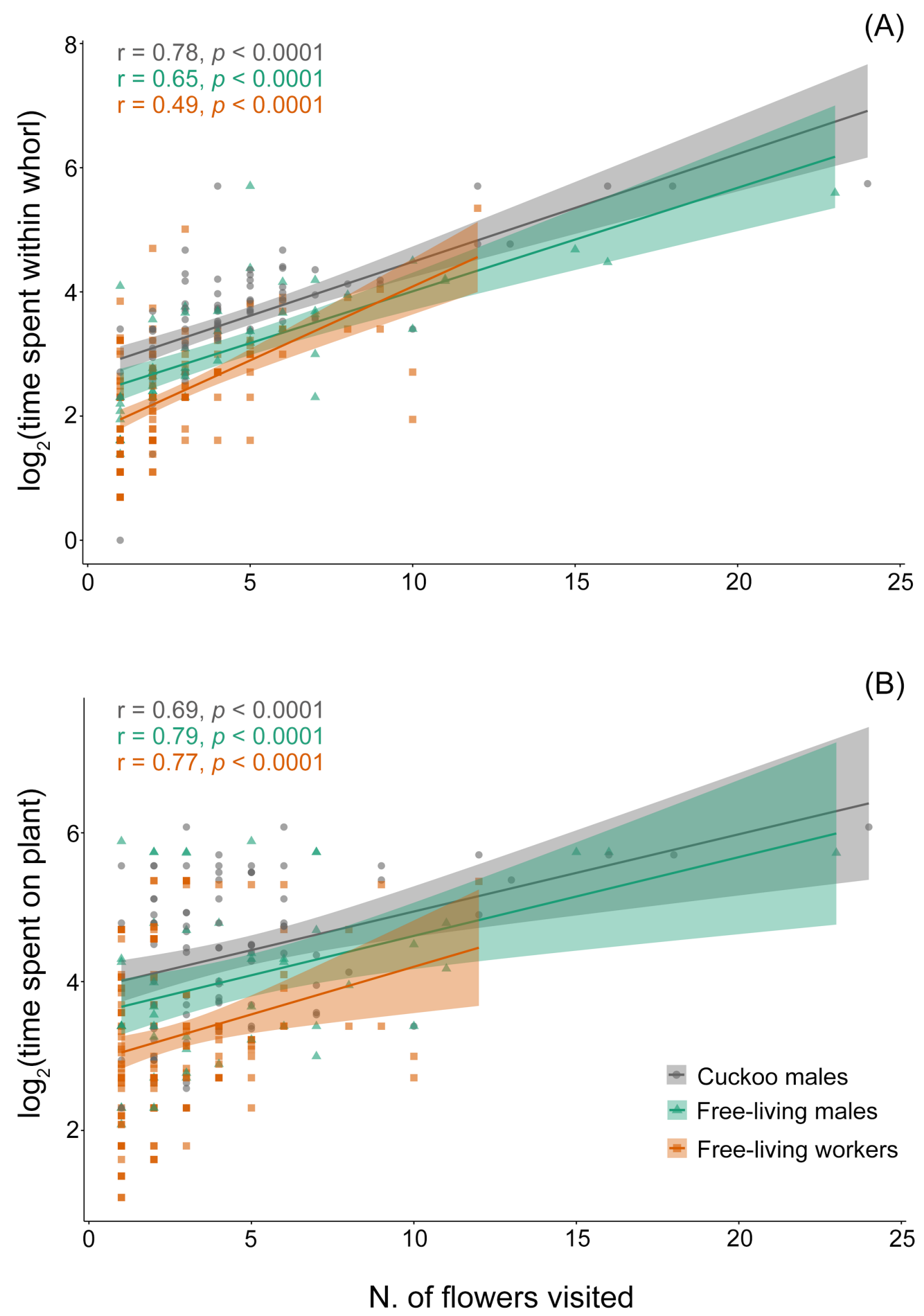

Figure 1 - Linear regressions and $95 \%$ confidence intervals between the number of visited flowers and the time (measured in seconds) spent (A) on flowers within whorl and (B) on the whole plant by cuckoo bumblebees and by free-living bumblebee males and workers. All cuckoo bumblebees were male. 
whorls and on the whole plant. Within-whorl correlation was highest for cuckoo bumblebees, intermediate for free-living bumblebee males and lowest for free-living bumblebee workers (Fig. 1A). Within-plant correlation was lower for cuckoo bumblebees and comparably higher for free-living bumblebee males and workers (Fig. 1B).

Cuckoo bumblebees spent significantly more time visiting flowers within each whorl (106.2 $\pm 25.7 \mathrm{~s})$ than both free-living bumblebee males $(33.4 \pm 5.2 \mathrm{~s}$; Table S1, coefficient contrast $=0.87, p<0.0001)$

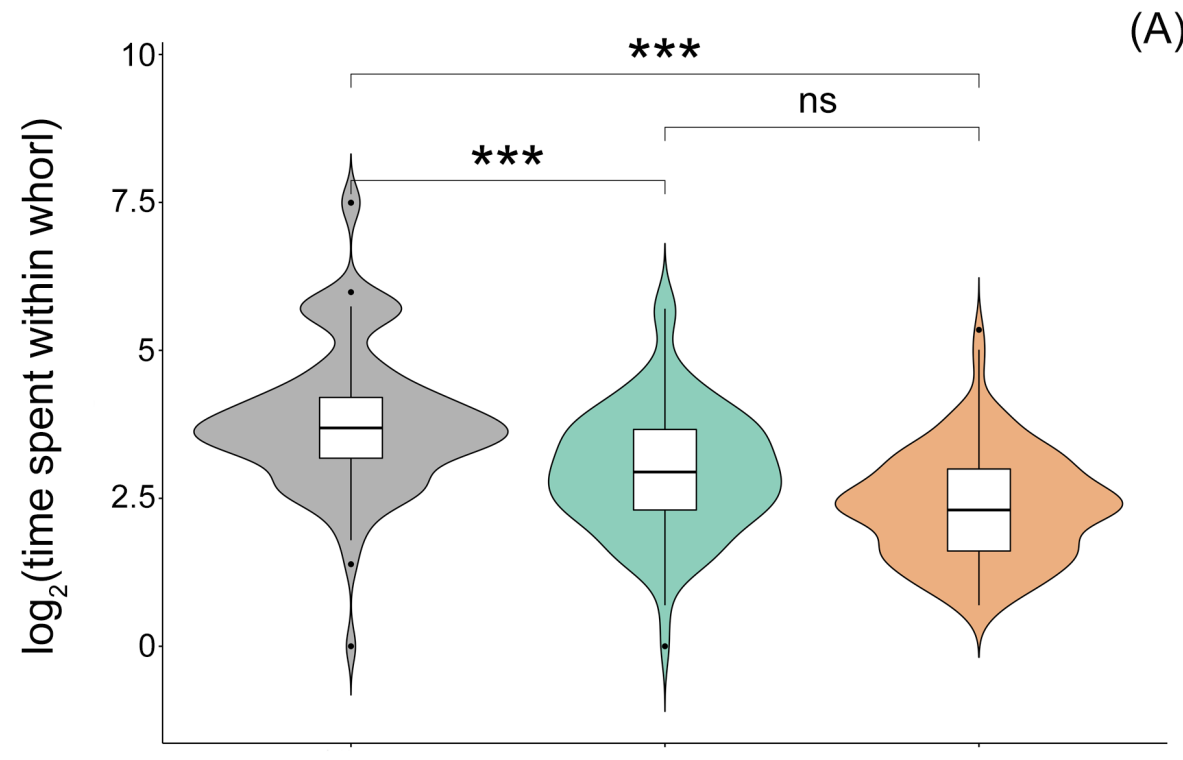

(A)

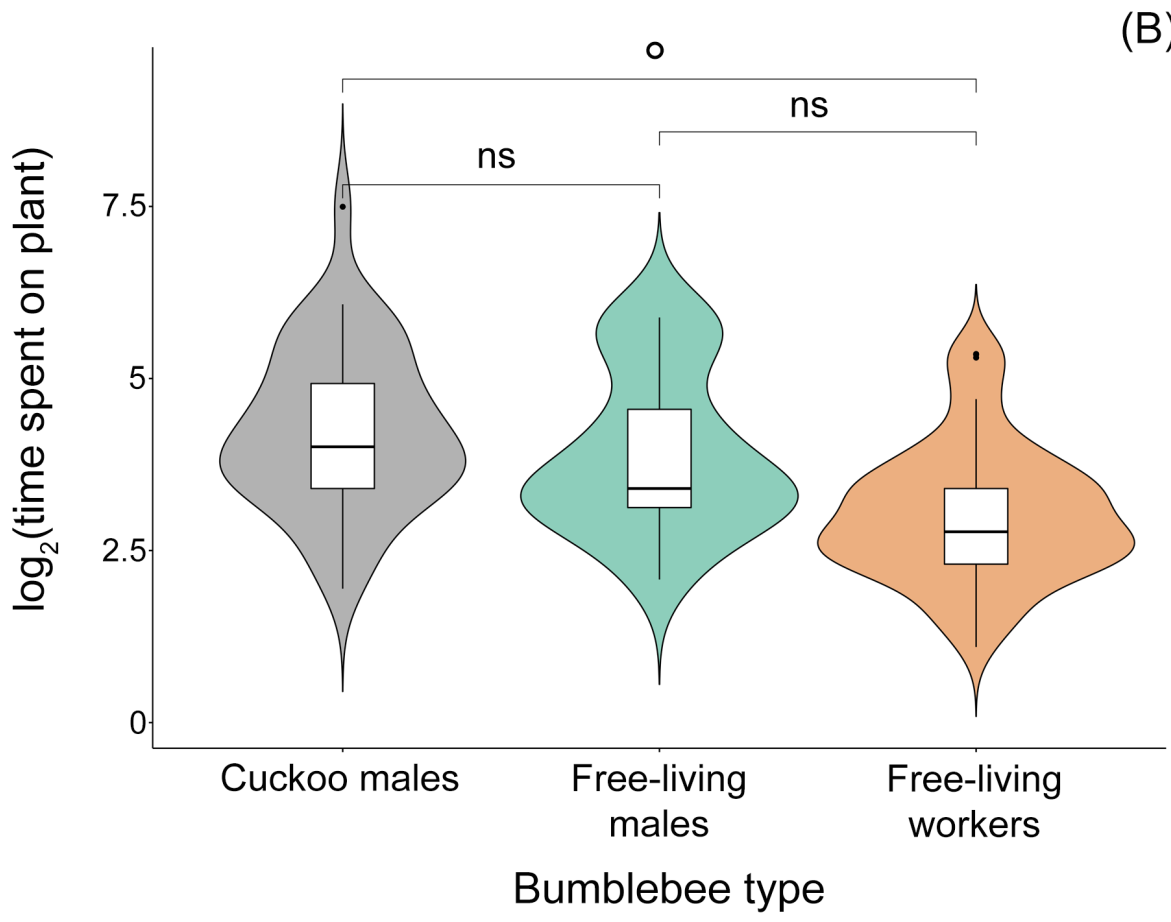

Figure 2 - Violin plots of time (measured in seconds) spent on flowers (A) within each whorl and (B) on the whole plant by bumblebee types (cuckoo bumblebee males, free-living bumblebee males and workers). All cuckoo bumblebees were males. ${ }^{\circ} p=0.059 ; *^{* *} p \leq 0.0001$. 
and workers $(16.5 \pm 1.9 \mathrm{~s}$; Table S1, coefficient contrast $=1.20, p<0.0001)$, which in turn did not significantly differ from each other (Fig. 2A, Table S1, coefficient contrast $=0.34, p=0.15$ ).

Cuckoo bumblebees spent almost significantly more time on flowers on the whole plant $(153.1 \pm 49.4$ seconds) than free-living bumblebee workers $(35.3 \pm 6.9 \mathrm{~s}$; Table $\mathrm{S} 2$, coefficient contrast $=0.69, p=$ $0.059)$ but not males $(97.0 \pm 24.4 \mathrm{~s}$; Figure $2 \mathrm{~B}$, Table S2, coefficient contrast $=0.30, p=0.52)$. Freeliving bumblebee males and workers did not spend significantly different amounts of time visiting plants (Fig. 2B, Table S2, coefficient contrast $=0.39, p=0.43$ ). The number of whorls displayed by plants did not affect the flower visitation time of bumblebees (Tables S2-S3).

Cuckoo bumblebees visited significantly more flowers per whorl $(4.74 \pm 0.4)$ than free-living bumblebee workers $(2.67 \pm 0.2)$, but no more than males $(4.73 \pm 0.6)$, while free-living bumblebee males visited significantly more flowers than workers (Fig. S1A, Table S4). We did not find significant differences in the number of flowers visited at the whole plant level between bumblebee types (Fig. S1B, Table S5).

Tables S1-S5 and Fig. S1A-B can be found in Appendices 1 and 2, respectively.

\section{Discussion}

In this article we explored differences in the flower-visiting behaviour of cuckoo and free-living bumblebees. We provide the first empirical evidence of slower and significantly longer flower visits performed by cuckoo bumblebees compared to free-living bumblebees. We found that male cuckoo bumblebees visited more flowers and spent more time during each visit than both free-living bumblebee workers and males at the whorl level, but these differences were less marked at the plant level. Freeliving bumblebee males visited more flowers than workers but not for significantly longer time periods.

\section{Flower-visiting behaviour}

The different behaviours observed between cuckoo bumblebee males and free-living bumblebee workers can be mainly related to different foraging needs. Bumblebee workers need to collect pollen for colony development, while at the same time keeping a positive balance between energy intake (through nectar) and the energy spent visiting flowers (HODGES \& WOLF 1981; PYKE 1984). By contrast, cuckoo bumblebee males, as free-living males, do not collect pollen and visit flowers mainly for nectar. Consequently, the need to optimise energy intake over expenditure during foraging bouts is probably less important for cuckoo bumblebees than for free-living bumblebee workers.

Bumblebee workers visited fewer flowers for slightly shorter periods than free-living males. Though differences in visit duration were not statistically significant, mainly because of the high response variability of free-living bumblebee males, the different observed behaviours remain biologically relevant and support previous literature (OSTEVIK et al. 2010; WOLF \& CHITTKA 2016). Shorter visits made by workers are likely driven by different foraging needs compared to males, as males do not collect pollen to sustain the colony similarly to cuckoo male bumblebees. Moreover, visits made by workers are usually driven by the quality and abundance of floral rewards, as workers tend to prioritize highly rewarding flowers to collect both pollen and nectar to optimize foraging bouts, while male visits are less constrained by reward availability (SMITH et al. 2019).

The longer visits and the higher number of flowers visited within whorls by cuckoo bumblebees cannot be attributed to different foraging requirements compared to free-living bumblebee males since neither of them provide pollen for the nest and mainly visit flowers for their own sustenance and to look for mates (GOULSON 2010; WOLF \& MORITZ 2014). A possible explanation can be deduced from the slow 
behaviour displayed by cuckoo bumblebees. Similarly to the only previous description of cuckoo foraging behaviour (PRYS-JONES \& CORBET 1991), we frequently observed almost lethargic movements by cuckoo bumblebees during flower visits within whorls of $G$. lutea. We hypothesize that differences between cuckoo and free-living male bumblebees can be linked to different mating periods. Cuckoo bumblebee females tend to usurp free-living bumblebee nests at the beginning of colony development, when only the few workers of the first brood have been produced (KREUTER et al. 2012; LHOMME et al. 2013). Moreover, cuckoo bumblebees start to lay male and female eggs within 10 days from invasion (Lhomme et al. 2013), while free-living bumblebees start to lay male eggs between 30 and 40 days after the emergence of the first brood, and the last group of diploid eggs laid before male eggs usually develops into gynes (BOGO et al. 2018). However, the developmental time of cuckoo and free-living bumblebee sexual morphs (males and gynes) is comparable (KÜPPER \& SCHWAMMBERGER 1995; BOGO et al. 2018). Consequently, a gap between the mating periods of cuckoo and free-living bumblebees can be expected. In our observations we only found cuckoo bumblebee males, suggesting that the peak flowering of $G$. lutea occurred when the mating period of cuckoo bumblebees was toward the end, therefore reducing the need for males to actively look for partners. By contrast, free-living bumblebees were likely still at the beginning of their mating period, compelling free-living male bumblebees to actively seek out partners and increase their mobility. In addition, cuckoo and free-living bumblebees may greatly differ in mating duration (e.g., 3 min versus more than 26 min, respectively; LHOMME et al. 2013), which can potentially affect male foraging behaviour, for example through distinct energetic requirements. Differences in the metabolism of cuckoo and free-living males may further emphasize behavioural differences. Further studies are needed to explore these possibilities.

\section{Implications for pollination}

Shorter visits made by worker bumblebees tend to favour constant foraging patterns and short-term floral specialization, which in turn can translate into a more efficient pollen dispersal between plants of a same species within a given population (SмITH et al. 2019). On the contrary, longer visits made by cuckoo bumblebees both within whorls and at the whole-plant level can likely increase the withinplant pollen flow (i.e., geitonogamy) and result in reduced plant fitness. Moreover, the higher number of flowers visited by cuckoo bumblebees, together with their sloppy foraging behaviour which increases the probability of touching receptive stigmas for longer time periods and with a larger body surface (personal observation AF, MG), suggests a further contribution to geitonogamous (i.e., between flowers on the same plant) pollen flow. The intermediate visitation time by male free-living bumblebees suggests that they may contribute intermediate pollination efficiency compared to cuckoos and workers, given their high potential for pollen transfer (OsteviK et al. 2010; Wolf \& MORITZ 2014; OGILVIE \& THOMSON 2015), while at the same time contributing to geitonogamous pollen transfer within plants of G. lutea.

Although we could not directly link bumblebee visits to plant fitness, we expect the longer flower visits of cuckoo bumblebees to reduce fruit set and seed set and germination. A previous study on the same population showed that self-pollinated flowers of $G$. lutea produced seeds with lower weight and germination rates compared to both open-pollinated and cross hand-pollinated flowers (Rossi et al. 2016). The reduced fitness can be partially explained by inbreeding depression or by intrinsic genetic problems (e.g. founder effect or bottleneck) as a consequence of the isolation from other natural populations (Rossi et al. 2016). However, the high abundance of cuckoo bumblebees observed in this study can act in addition to these factors and further reduce plant fitness in the study population. The transfer of pollen within plants facilitated by the longer visits of cuckoo bumblebees can increase geitonogamy and pollen discounting (BRUNET 2005), ultimately reducing plant fitness.

Among the 350 bumblebees observed in this study, almost a third (28.9\%) were cuckoo bumblebee males. Because they are among the main pollinators of G. lutea (Rossi et al. 2014), we expect them to play 
an important role in the pollination success and ultimately on population persistence. Further analyses aimed directly at evaluating the effects of bumblebee visits on plant fitness would help understand the balance between positive (e.g., pollen flow) and negative (e.g., geitonogamy) contributions of cuckoos compared to free-living bumblebees. Given the widespread presence of cuckoo bumblebees, we expect that their visits can significantly affect the reproductive success of several plant species, and encourage future research to directly address this overlooked topic.

\section{Data accessibility}

Data and R scripts for analyses are available online: https://doi.org/10.5281/zenodo.5161010

\section{Acknowledgements}

We thank Natasha de Manincor and the students that helped with field work and data collection. We thank Patrick Lhomme, Silvio Erler and two anonymous reviewers for providing useful comments on the manuscript. MG conceived the study; AF, GB, LB and MG collected data and identified bumblebees; $\mathrm{AF}$ and FM analysed data; $\mathrm{AF}$ and GB wrote the first draft and all authors contributed to the final version of the manuscript. Version 1.2 of this preprint has been peer-reviewed and recommended by Peer Community In Zoology (https://doi.org/10.24072/pci.zool.100009).

\section{Conflict of interest disclosure}

The authors of this preprint declare that they have no financial conflict of interest with the content of this article.

\section{References}

ALFORD D. (1975). Bumblebees. Davis-Poynter, London.

ANDRIKopoulos C. \& CANE J. (2018). Comparative pollination efficacies of five bee species on raspberry. Journal of Economic Entomology 111: 2513-2519. https://doi.org/10.1093/jee/toy226

BARTON K. (2019). MuMIn: Multi-Model Inference. R package version 1.43.17.

Avalaible from https://CRAN.R-project.org/package=MuMIn

BATEMAN R. \& RUdALl P. (2014). Bumblebee-mediated pollination of English populations of the Military Orchid (Orchis militaris): its possible relevance to functional morphology, life history and climate change. New Journal of Botany 4: 122-133. https://doi.org/10.1179/2042349714Y.0000000048

Bates D., Mächler M., BolKer B.M. \& WALKer S.C. (2015). Fitting Linear Mixed-Effects Models Using lme4. Journal of Statistical Software 67: 1-48. https://doi.org/10.18637/jss.v067.i01

Bogo G., De Manincor N., Fisogni A., Galloni M., Zavatta L. \& Bortolotti L. (2018). Different reproductive strategies and their possible relation to inbreeding risk in the bumble bee Bombus terrestris. Insectes Sociaux 65: 289-295. https://doi.org/10.1007/s00040-018-0611-1

BRUNET J. (2005). Plant-pollinator interactions and pollen dispersal. In: DAFNI A., KEVAN P.G. \& Husband B. (eds) Practical pollination biology: 56-82. Enviroquest Ltd, Cambridge, Ontario, Canada.

BURNHAM K. \& ANDERSON D. (2002). Information and likelihood theory: a basis for model selection and inference. In: Model Selection And Multimodel Inference: a Practical Information-Theoretic Approach: 49-97. Springer-Verlag, New York. 
FISHER R. (1987). Queen-worker conflict and social parasitism in bumble bees (Hymenoptera: Apidae). Animal Behaviour 35: 1026-1036. https://doi.org/10.1016/S0003-3472(87)80159-8

FRÜND J., DORMANN C.F., HOLZSCHUH A. \& TSCHARNTKE T. (2013). Bee diversity effects on pollination depend on functional complementarity and niche shifts. Ecology 94: 2042-2054.

https://doi.org/10.1890/12-1620.1

Goulson D. (2010). Bumblebees. Behaviour, Ecology, and Conservation. Oxford University Press, Oxford.

Goulson D., Lye G.C. \& DARVILl B. (2008). Decline and conservation of bumble bees. Annual Review of Entomology 53: 191-208. https://doi.org/10.1146/annurev.ento.53.103106.093454

HodGES C. \& WOLF L. (1981). Optimal foraging in bumblebees: why is nectar left behind in flowers? Behavioral Ecology and Sociobiology 9: 41-44. https://doi.org/doi:10.1007/bf00299851

JenNersten O., Morse D.H. \& O'NeIL P. (1991). Movements of Male and Worker Bumblebees on and between Flowers. Oikos 62: 319-324. https://doi.org/10.2307/3545496

Kreuter K., Bunk E., LÜCKemeyer A., Twele R., Francke W. \& Ayasse M. (2012). How the social parasitic bumblebee Bombus bohemicus sneaks into power of reproduction. Behavioral Ecology and Sociobiology 66: 475-486. https://doi.org/10.1007/s00265-011-1294-z

KÜPPER G. \& SchwAmmberger K. (1995). Social parasitism in bumble bees (Hymenoptera, Apidae): observations of Psithyrus sylvestris in Bombus pratorum nests. Apidologie 26: 245-254.

https://doi.org/10.1051/apido:19950306

LENTH R. (2020). Emmeans: Estimated Marginal Means, aka Least-Squares Means. R package version 1.5.1. Available from https://CRAN.R-project.org/package=emmeans

LHOMME P. \& HiNeS H.M. (2019). Ecology and evolution of cuckoo bumble bees. Annals of the Entomological Society of America 112: 122-140. https://doi.org/10.1093/aesa/say031

Lhomme P., Sramkova A., Kreuter K., LecocQ T., Rasmont P. \& Ayasse M. (2013). A method for year-round rearing of cuckoo bumblebees (Hymenoptera: Apoidea: Bombus subgenus Psithyrus). Annales de la Société Entomologique de France 49: 117-125.

https://doi.org/10.1080/00379271.2013.774949

Lhomme P., Williams S.D., Ghisbain G., Martinet B., Gérard M. \& Hines H.M. (2021). Diversification pattern of the widespread Holarctic cuckoo bumble bee, Bombus flavidus (Hymenoptera: Apidae): the east side story. Insect Systematics and Diversity 5: 1-15. https://doi.org/10.1093/isd/ixab007

OGILVIE J.E. \& THOMson J.D. (2015). Male bumble bees are important pollinators of a late-blooming plant. Arthropod-Plant Interactions 9: 205-213. https://doi.org/10.1007/s11829-015-9368-x

Ollerton J., Killick A., Lamborn E., Watts S. \& Whiston M. (2007). Multiple meanings and modes: on the many ways to be a generalist flower. Taxon 56: 717-728. https://doi.org/10.2307/25065855

OsteViK K.L., MANson J.S. \& ThOMson J.D. (2010). Pollination potential of male bumble bees (Bombus impatiens): movement patterns and pollen-transfer efficiency. Journal of Pollination Ecology 2:21-26. https://doi.org/10.26786/1920-7603(2010)3

Pellissier V., Muratet A., Verfaillie F. \& Machon N. (2012). Pollination success of Lotus corniculatus (L.) in an urban context. Acta Oecologica 39: 94-100.

https://doi.org/10.1016/j.actao.2012.01.008

Prys-Jones O. \& Corbet S. (1991). Bumblebees. Richmond Publishing Company, Slough, UK. 
PYKE G.H. (1984). Optimal foraging theory: A critical review. Annual Review of Ecology and Systematics 15: 523-575. https://doi.org/10.1146/annurev.es.15.110184.002515

R CORE TEAM (2019). R: A language and environment for statistical computing. R Foundation for Statistical Computing, Vienna, Austria.

Rossi M., Fisogni A. \& GAlloni M. (2015). Biosystematic studies on the mountain plant Gentiana lutea L. reveal variability in reproductive traits among subspecies. Plant Ecology \& Diversity 9: 97-104. https://doi.org/10.1080/17550874.2015.1074625

Rossi M., Fisogni A. \& GALLONI M. (2016). The effect of pollination mode on seed performance of Gentiana lutea: a laboratory evaluation of seed germinability. Nordic Journal of Botany 34: 761-768. https://doi.org/10.1111/njb.01177

Rossi M., Fisogni A., NePI M., Quaranta M. \& Galloni M. (2014). Bouncy versus idles: On the different role of pollinators in the generalist Gentiana lutea L. Flora 209: 164-171.

https://doi.org/10.1016/j.flora.2014.02.002

Russell A.L., Morrison S.J., Moschonas E.H. \& PAPAJ D.R. (2017). Patterns of pollen and nectar foraging specialization by bumblebees over multiple timescales using RFID. Scientific Reports 7: 42448. https://doi.org/10.1038/srep42448

Smith G.P., BRonstein J.L. \& PAPAJ D.R. (2019). Sex differences in pollinator behavior: Patterns across species and consequences for the mutualism. Journal of Animal Ecology 88: 971-985.

https://doi.org/10.1111/1365-2656.12988

THOMSON J. \& GoOdell K. (2001). Pollen removal and deposition by honeybee and bumblebee visitors to apple and almond flowers. Journal of Applied Ecology 38: 1032-1044.

https://doi.org/10.1046/j.1365-2664.2001.00657.x

Velthuis H. \& van Doorn A. (2006) A century of advances in bumblebee domestication and the economic and environmental aspects of its commercialization for pollination. Apidologie 37: 421-451. https://doi.org/10.1051/apido:2006019

WickHAм H. (2016). ggplot2: elegant graphics for data analysis. Springer-Verlag, New York.

Wolf S. \& ChITTKA L. (2016). Male bumblebees, Bombus terrestris, perform equally well as workers in a serial colour-learning task. Animal Behaviour 111: 147-155.

https://doi.org/10.1016/j.anbehav.2015.10.009

WOLF S \& MORITZ R. (2014). The pollination potential of free-foraging bumblebee (Bombus spp.) males (Hymenoptera: Apidae). Apidologie 45: 440-450. https://doi.org/10.1007/s13592-013-0259-9

Manuscript received: 12 November 2021

Manuscript accepted: 18 November 2021

Published on: 15 December 2021

Branch editor: Isa Schön

\section{Appendix}

Appendix 1 and 2 are available online: https://doi.org/10.5281/zenodo.5648350 